Jihene Maatoug, Jihene Sahli*, Imed Harrabi, Firas Chouikha, Sonia Hmad, Emna Dendana, Sihem Ben Fredj, Slim Slama, Mustafa al'Absi, Harry Lando and Hassen Ghannem

\title{
Assessment of the validity of self-reported smoking status among schoolchildren in Sousse, Tunisia
}

DOI 10.1515/ijamh-2015-0013

Received February 17, 2015; accepted May 6, 2015; previously published online September 11, 2015

\section{Abstract}

Introduction: Tobacco use, which begins in adolescence and childhood and continues in later life, is the major avoidable risk for non-communicable diseases and death in the world. Self-reports have frequently been used to estimate smoking prevalence and health consequences. This study explores the validity of self-reports of smoking behavior among schoolchildren in Tunisia.

Materials and methods: This study was conducted in March 2014 among a sample of 147 schoolchildren randomly selected. Data concerning the smoking habit were collected by a questionnaire designed for the purposes of this work. Then, exhaled CO, a biochemical marker of smoke exposure, was measured using piCO+Smokerlyzer ${ }^{\circledR}$ breath CO monitor among participants. Sensitivity and specificity of self-reports were calculated.

Results: The prevalence of reported smoking was 9.5\% with $16.7 \%$ and $1.7 \%$ respectively among boys and girls. Their mean age was $14.5 \pm 1.28$ years old. When considering $4 \mathrm{ppm}$ as the cut-off level of breath CO, sensitivity and specificity of self-reports were $100 \%$ and $93.7 \%$, respectively. But at a breath CO cut-off of 3 ppm, self-reporting was $62.5 \%$ sensitive and $93.5 \%$ specific.

*Corresponding author: Jihene Sahli, Department of Epidemiology, University Hospital Farhat Hached, Sousse, Tunisia, E-mail: jihene.sahli19@gmail.com

Jihene Maatoug, Imed Harrabi, Firas Chouikha, Sonia Hmad, Emna Dendana, Sihem Ben Fredj and Hassen Ghannem: Department of Epidemiology, University Hospital Farhat Hached, Sousse, Tunisia Slim Slama: Department of Community Medicine, Primary care and Emergency, University Hospitals of Geneva, Switzerland Mustafa al'Absi: Duluth Medical Research Institute, University of Minnesota, Duluth, MN, USA

Harry Lando: Department of Epidemiology and Community Health, University of Minnesota, Duluth, MN, USA
Conclusion: According to our findings, we suggest that self-reports can be considered as a good tool to be used with a reasonable confidence to assess the smoking status.

Keywords: carbone monoxide; self-report; smoking.

\section{Introduction}

Tobacco use is the major avoidable risk for non-communicable diseases and death in the world. It is known that the onset of tobacco use begins in adolescence and childhood and continues in later life $(1,2)$. Assessing a true status of smoking is important to allocate resources, set and assess anti-smoking policies (3), especially around adolescence which offer opportunities to health benefits through prevention and early clinical intervention (4).

Self-reports have frequently been used to estimate smoking prevalence and health consequences. They are also used to determine the efficacy of interventions conducted to promote smoking cessation (5). However, the validity of self-reports, particularly of socially undesirable behaviors such us smoking, was debatable in the literature $(3,5-7)$. The increasing social unacceptability of smoking (8), fears of being reprimanded and concerns about confidentiality especially among adolescents (9) may be sources of an underreporting of the smoking habit and in consequence an underestimation of the true prevalence of cigarette smoking. To assess the validity of self-reports, authors used to compare responses from selfreport to the measures of biochemical markers. A variety of biochemical markers is available such as measures based on thiocyanate, nicotine, cotinine, and carbon monoxide. Availability, cost, and ease of administration are not same in these different measures. From these tests, the measurement of carbon monoxide in exhaled air is cheaper, easier to apply, does not require special technical background, and may provide an immediate, non-invasive method to assess recent smoking status $(6,10-12)$. 
Considering the above, we have conducted this study among a sample of schoolchildren in the delegation of Sousse in Tunisia for the purpose to explore the accuracy of self-reports of smoking behavior and determine whether self-report is a reliable tool to assess the prevalence of smokers in our studies. This study compared selfreport and biochemical verification using exhaled carbon monoxide among the participants.

\section{Materials and methods}

\section{Population study}

In March 2014, we made a random cluster sampling of seven classes from the schoolchildren of Khezema Ouest College in the delegation of Sousse in Tunisia. The number of schoolchildren, who were present in each class the day of the survey ranged from 17 to 26 , resulting in a total of 147 participants.

\section{Data collection}

A questionnaire was designed for the purposes of this work. It contains sections exploring individual characteristics, smoking status, and exposure to passive smoking. It was self-administered with the presence of interviewer.

Exhaled CO was measured using piCO+Smokerlyzer ${ }^{\circledR}$ breath CO monitor (SN PP 043276).

After a deep inspiration followed by apnea eight to ten seconds or more, the subject exhales continuously during a calm expiration of five to ten seconds, through the mouth into the disposable $\mathrm{CO}$ analyzer.

The participants were informed by the measures of expired air $\mathrm{CO}$ after the questionnaire's administration.

Before beginning the measures, a demonstration of the technique was made to all the participants.

\section{Definition of variables}

A smoker was defined as a person who consumed tobacco at least once the last month.

\section{Data capture and analysis}

Data capture and analysis were performed using SPSS for Windows 10.0 (SPSS Inc., Chicago, IL, USA).
Categorical variables were summarized with absolute and relative frequencies.

Sensitivity and specificity of self-reports were calculated.

Sensitivity is the percentage of true positives: the percentage of respondents who reported being smokers among those classified as smokers based on breath CO concentrations.

Specificity is the percentage of true negatives: the percentage of respondents who reported being non-smokers among those classified as non-smokers based on breath CO concentrations.

\section{Ethical considerations}

We have obtained the consent of parents' participants and participants themselves prior to conducting the study. The study has been approved by the Ethical Committee of University Hospital Farhat Hached.

\section{Results}

In total, 147 schoolchildren were included in this study with $53.8 \%$ male and $46.2 \%$ female, respectively. Their ages ranged from 11 to 18 with a mean of $13.42 \pm 1.39$ years old.

The prevalence of reported smoking was 9.5\% with $16.7 \%$ and $1.7 \%$, respectively, among boys and girls $(\mathrm{p}=0.002)$. Their mean age was $14.5 \pm 1.28$ years old, ranging from 12 to 17 years old.

Eighty-nine (60.5\%) among the participants said that they were exposed to passive smoking the day before.

The mean of exhaled $\mathrm{CO}$ in all participants was $1.04 \pm 1.1 \mathrm{ppm}$ with extremes ranging from 0 to $8 \mathrm{ppm}$, and it was significantly higher among smokers $(p=0.01)$ (Table 1).

CO levels greater than or equal to $3 \mathrm{ppm}$ were found among three non-smokers ( $3 \mathrm{ppm}$ ) and five smokers. The daily smokers had breath CO levels more than $4 \mathrm{ppm}$. One daily smoker had a CO level of 8 ppm (Tables 2 and 3).

Exhaled CO levels greater than or equal to $3 \mathrm{ppm}$ were found in three schoolchildren who reported not smoking. One student who was a boy of 13 years old reported a nonexposure to passive smoking the day before the survey. The two other schoolchildren who were girls aged 15 and 17 years old, reported being exposed to passive smoking during the last day (Table 4).

Table 1: Characteristics of the sample.

\begin{tabular}{|c|c|c|c|}
\hline & Smokers & Non-smokers & p-Value \\
\hline Age, mean $\pm S D$ & $14.50 \pm 1.28$ & $13.30 \pm 1.36$ & 0.002 \\
\hline Presence of passive smoking exposure yesterday, \% & 85.7 & 57.9 & 0.04 \\
\hline Exhaled CO levels, mean \pm SD & $2.71 \pm 2.30$ & $0.86 \pm 0.71$ & 0.01 \\
\hline
\end{tabular}


Table 2: Exhaled CO levels according to self-reported smoking status among schoolchildren.

\begin{tabular}{lrrrr}
\hline & $\mathbf{0 - 2} \mathbf{~ p p m}$ & $\mathbf{3} \mathbf{p p m}$ & 4-8 ppm & \\
\hline Non-smokers & 130 & 3 & 0 & 133 \\
Smokers & 9 & 0 & 5 & 14 \\
\hline
\end{tabular}

Table 3: Exhaled CO levels according to the frequency of smoking during the last month among smokers.

\begin{tabular}{lrrr}
\hline & $\mathbf{0 - 2} \mathbf{p p m}$ & $\mathbf{3 ~ p p m}$ & 4-8 ppm \\
\hline 1-2 days & 9 & 0 & 0 \\
$3-5$ days & 0 & 0 & 1 \\
30 days & 0 & 0 & 4 \\
\hline
\end{tabular}

Table 4: Exhaled CO levels according to the last-day passive smoking exposure in non-smokers.

\begin{tabular}{lrr}
\hline & 0-2 ppm & 3 ppm \\
\hline Not exposed to passive smoking yesterday & 55 & 1 \\
Exposed to passive smoking yesterday & 75 & 2 \\
\hline
\end{tabular}

Sensibility and specificity of self-reports varied with the variation of the cut-off level of the breath CO.

When considering $3 \mathrm{ppm}$ as the cut-off level of expired CO, sensibility and specificity of self-reports in assessing the smoking status among participants were $62.5 \%$ and $93.5 \%$, respectively.

When considering $4 \mathrm{ppm}$ as the cut-off level of expired CO ( $>3 \mathrm{ppm})$, sensibility and specificity of self-reports in assessing the smoking status among participants were $100 \%$ and $93.7 \%$, respectively.

\section{Discussion}

Regional and national data concerning smoking prevalence, patterns, and consequences were based on selfreports; however, the validity of self-reports of a smoking habit is often questionable in situations involving social pressure $(6,13,14)$. Therefore, a number of biochemical markers have been used to assess objectively smoking behavior $(5,6)$.

\section{CO biomarker}

$\mathrm{CO}$ is a non-specific biological marker of smoking, and it reflects the intensity of tobacco smoke inhalation.
It has both endogenous and mainly exogenous origin. Endogenous CO production comes from the catabolism of hemoglobin. Exogenous origin comes from the incomplete combustion of any organic molecule. It is present in the primary current smoke inhaled by the smoker, but also in the secondary current smoke from cigarettes outside periods of inhalation and the tertiary current smoke exhaled by the smoker after inhalation. CO has a strong affinity for hemoglobin producing carboxyhemoglobin $(\mathrm{COHb})(15)$. The dissociation of $\mathrm{COHb}$ occurs at the lungs, where $\mathrm{CO}$ is exhaled (15). Because of its short halflife which is about $2-6 \mathrm{~h}$, this test depends on the time elapsed since the last cigarette smoked. It is also shown that it is less reliable in low-level smokers (16).

No consensus was found in the literature for a cut-off level to differentiate smokers and non-smokers (15). The cut-off values vary from 3 to $10 \mathrm{ppm}$ in adult samples $(6,17-20)$.

In our study, the prevalence of smokers assessed by self-reports among the participants was $9.5 \%$ with a sensitivity and specificity of $100 \%$ and $93.7 \%$, respectively, when considering $4 \mathrm{ppm}$ as the cut-off level of the breath $\mathrm{CO}$.

In the study conducted among adolescents, Vançelik et al. (21), found that the mean exhaled CO levels of regular, occasional, and non-smokers were 7.23 \pm 1.5 , 4.0 \pm 2.1 , and $2.5 \pm 2.4 \mathrm{ppm}$, respectively. These exhaled CO levels among adolescents were quite lower than those of adults, which were studied in Turkish young adults (10). In our study, lower means among the whole population study and among smokers were found. It can be explained by the age of our participants and the low number of daily smokers among them.

From another side, the results of Cropsey et al. (19) suggest that CO cutoffs higher than 3 ppm may misclassify some smokers as non-smokers and underestimate the prevalence of smoking.

Groman et al. (22) noted that the absorption of alcohol could increase the rate of up to $15 \mathrm{ppm}$. Furthermore, Lagrue et al. (23) reported that a high consumption of rich sweets polyols could increase the rate of expired CO.

Low et al. (24) found in smokers who had not smoked in the last 24 hours, the minimum CO level was $1.5 \mathrm{ppm}$, and the maximum CO level was $18 \mathrm{ppm}$.

In our study, the mean of exhaled CO levels was significantly higher among smokers $(2.71 \pm 2.30 \mathrm{ppm}$ among smokers versus $0.86 \pm 0.71 \mathrm{ppm}$ among non-smokers; $\mathrm{p}=0.01$ ). Exhaled CO levels equal to $3 \mathrm{ppm}$ were found in three schoolchildren who reported being non-smokers. One of them reported a non-exposure to passive smoking the day before the survey. The two other schoolchildren 
reported being exposed to passive smoking during the last day. Considering our results, we cannot decide which level, 3 or 4 ppm can be considered as a cut-off level for detecting smokers from non-smokers in our sample. If we consider 3 ppm as the cut-off level of breath CO, sensitivity and specificity of self-reports were $62.5 \%$ and $93.5 \%$, respectively, and we can suggest that perhaps there is an inaccurate response to the questionnaire in one case due to social desirability bias. In the two other cases, who were girls, their measures of exhaled CO could be explained by their exposure to passive smoking the day before the survey. If we consider $4 \mathrm{ppm}$ as the cut-off level of CO, self-reporting was $100 \%$ sensitive and $93.7 \%$ specific, and in consequence, we can suggest that selfreported smoking status can be considered as reliable to assess the prevalence of smoking status in our last and future studies.

Javors et al. (20) found that the highest combined sensitivity and specificity $(71.5 \% ; 84.8 \%)$ was observed at a breath CO cut-off level of 3 ppm and at a breath CO cut-off of $8 \mathrm{ppm}$. Many smokers would be falsely classified as abstinent.

In the paper of Usmani et al. (25), cut-off levels of $2 \mathrm{ppm}$ and $3 \mathrm{ppm}$ were suggested with reasonable accuracy to discriminate during pregnancy of women who are smokers.

But in a study conducted in India comparing oral questionnaire to breathe carbon monoxide in the assessment of tobacco smoking status (26), authors found that respondents who were non-smokers per oral questionnaires underreported their smoking status with maximum underreporting level of 30\%. They found that sensitivity and specificity of self-reporting were $75 \%$ and $76 \%$, respectively.

\section{Other biomarkers}

Other biochemical markers are used to discriminate smoking status including thiocyanate, nicotine, and cotinine.

Thiocyanate measure is easy to determine, but it may be influenced by diet. It is not helpful in detecting very low level smokers $(27,28)$.

Nicotine is not suitable as a measure to assess smoking status because it has a short half-life of 2 hours in the blood (27).

Cotinine, a major metabolite of nicotine, has the advantage of being specific to tobacco.

Cotinine in the plasma, urine, or saliva has been shown to be more sensitive and specific to distinguish tobacco smoke exposure and in consequence to validate reports than other biochemical tests $(5,6)$. But it requires expensive laboratory instrumentation.

The study of Post et al. (29), confirms the reliability of adolescents' self-reported tobacco use. They explained that the discordance between self-reported use and cotinine concentrations can be due to the irregular use of tobacco in this age group.

In their study assessing the validity of adolescent selfreported smoking using measures of carbon monoxide, salivary cotinine, and salivary thiocyanate, Dolcini et al. (30), found that cotinine had the highest sensitivity and specificity, and prevalence estimates of smoking were similar with self-reports and cotinine.

Wong et al. (31) found that sensitivity and specificity of self-reports were $91.6 \%$ and $98.3 \%$, respectively, and concluded to a non-significant difference between national estimates of smoking prevalence in Canada based on self-report versus urinary cotinine concentration. Studts et al. (32) showed that self-reported smoking status and biochemical validation measured via urinary cotinine levels were highly concordant among a high-risk sample of participants in a lung cancer screening trial.

In the literature, biochemical measures were criticized $(5,33,34)$. Errors in smoking measures using biochemical markers can be obtained because of the variability in the manner and the patterns of smoking $(5,17)$. They are relatively insensitive to the low levels of smoking and experimental smoking characteristic of adolescents (35).

According to the meta-analysis of Patrick et al. (5), biochemical tests are more difficult to obtain than selfreports, are expensive, and validate smoking status only near the time of specimen collection. They also can be invasive and increases refusal rates (5).

To assess validity of self-report risk behavior such us tobacco use, other methods are available such us random response technique (34). On another side, selfadministered questionnaires which have greater privacy, produce higher prevalence estimates of smoking than did interviewer-administered questionnaires, but only among adolescents (36).

In a pilot study (9) which was conducted to examine self-reported response distortion in adolescents who received a brief intervention to reduce their smoking, the authors concluded that self-reported misreports can also be useful and complementary to the techniques determining the concordance between self-reports and biochemical tests (9).

But despite their limitations, biochemical measures are often considered the gold standard in validation studies because they are believed to be more objective. 
Our study suggests an acceptable reliability of selfreported smoking status validated by $\mathrm{CO}$ biomarker; however, it presented some limits because it was conducted among a small sample and did not assess the quantity of cigarettes smoked and the time since the last cigarette.

\section{Conclusion}

According to our findings, we can suggest that self-reports can be considered as a good tool to be used with a reasonable confidence to assess the smoking status. Further research needs to be conducted to validate the cut-off level of CO that could distinguish smokers from non-smokers. We can also conduct another study to validate self-reports of the smoking status among the general population using another biochemical test such us salivary or urinary cotinine.

Acknowledgments: This study was supported by award $n^{\circ}$ R56TW009265 from the Fogarty International Center of the National Institute of Health.

\section{References}

1. WHO report on the global tobacco epidemic, 2011. Warning about the dangers of tobacco. [Cited 2015 Jan 8] Available at: http:// whqlibdoc.who.int/publications/2011/9789240687813_eng. pdf?ua $=1$.

2. Gore FM, Bloem PJ, Patton GC, Ferguson J, Joseph V, et al. Global burden of disease in young people aged 10-24 years: a systematic analysis. Lancet 2011;377:2093-102.

3. Connor Gorber S, Schofield-Hurwitz S, Hardt J, Levasseur G, Tremblay $M$. The accuracy of self-reported smoking: a systematic review of the relationship between self-reported and cotinineassessed smoking status. Nicotine Tob Res 2009;11:12-24.

4. Patton GC, Coffey C, Cappa C, Currie D, Riley L, et al. Health of the world's adolescents: a synthesis of internationally comparable data. Lancet 2012:379:1665-75.

5. Patrick DL, Cheadle A, Thompson DC, Diehr P, Koepsell T, et al. The validity of self-reported smoking: a review and meta-analysis. Am J Public Health 1994:84:1086-93.

6. Jarvis MJ, Tunstall-Pedoe H, Feyerabend C, Vesey C, Saloojee Y. Comparison of tests used to distinguish smokers from nonsmokers. Am J Public Health 1987;77:1435-8.

7. Fendrich M, Mackesy-Amiti ME, Johnson TP, Hubbell A, Wislar JS Tobacco-reporting validity in an epidemiological drug-use survey. Addict Behav 2005;30:175-81.

8. Sillett RW, Wilson MB, Malcolm RE, Ball KP. Deception among smokers. Br Med J 1978;2:1185-6.

9. Stein LAR, Colby SM, O’Leary TA, Monti PM, Rohsenow DJ, et al. Response distortion in adolescents who smoke: a pilot study. J Drug Educ 2002;32:271-86
10. Deveci SE, Deveci F, Açik Y, Ozan AT. The measurement of exhaled carbon monoxide in healthy smokers and non-smokers. Respir Med 2004;98:551-6.

11. Sandberg A, Sköld CM, Grunewald J, Eklund A, Wheelock ÅM. Assessing recent smoking status by measuring exhaled carbon monoxide levels. PLoS One 2011;6:e28864.

12. Jarvis MJ, Russell MAH, Saloojee Y. Expired air carbon monoxide: a simple breath test of tobacco smoke intake. Br Med J 1980;281:484-5.

13. Murray RP, Connett JE, Lauger GG, Voelker HT. Error in smoking measures: effects of intervention on relations of cotinine and carbon monoxide to self-reported smoking. Am J Public Health 1993;83:1251-7.

14. Rebagliato M. Validation of self-reported smoking. J Epidemiol Community Health 2002;56:163-4.

15. Underner M, Peiffer G. Interpretation of exhaled CO levels in studies on smoking. Rev Mal Respir 2010;27:293-300.

16. Frederiksen LW, Martin JE. Carbon monoxide and smoking behavior. Addict Behav 1979;4:21-30.

17. Vogt TM, Selvin S, Widdowson G, Hulley SB. Expired air carbon monoxide and serum thiocyanate as objective measures of cigarette exposure. Am J Public Health 1977;67:545-9.

18. Ruth KJ, Neaton JD. Evaluation of two biological markers of tobacco exposure. MRFIT Research Group. Prev Med 1991;20:574-89.

19. Cropsey KL, Eldridge GD, Weaver MF, Villalobos GC, Stitzer ML. Expired carbon monoxide levels in self-reported smokers and nonsmokers in prison. Nicotine Tob Res 2006;8:653-9.

20. Javors MA, Hatch JP, Lamb RJ. Cut-off levels for breath carbon monoxide as a marker for cigarette smoking. Addiction 2005;100:59-167.

21. Vançelik S, Beyhun NE, Acemoglu H. Interactions between exhaled CO, smoking status and nicotine dependency in a sample of Turkish adolescents. Turk J Pediatr 2009;51:56-64.

22. Groman E, Riemerth A, Bernhard G, Appeltauer G, Schuster B, et al. Can carbon monoxide analysers be fuelled by alcohol intake? Tob Control 2006;15:143.

23. Lagrue G, Diviné C, Dalle M, Cormier S, Maurel A. Intérêt de la mesure du CO dans l'air expiré dans les maladies vasculaires. Sang ThromboseVaiss 2004;16:389-91.

24. Low ECT, Ong MCC, Tan M. Breath carbonmonoxide as an indication of smoking habit in the military setting. Singapore Med J 2004;45:578-82.

25. Usmani ZC, Craig P, Shipton D, Tappin D. Comparison of CO breath testing and women's self-reporting of smoking behaviour for identifying smoking during pregnancy. Subst Abuse Treat Prev Policy 2008;3:4.

26. Aggarwal P, Varshney S, Kandpal SD, Gupta D. Tobacco smoking status as assessed by oral questionnaire results 30\% underreporting by adult males in reural India: a confirmatory comparison by xhaled breath carbon monoxide analysis. J Family Med Prim Care 2014;3:199-203.

27. Parker DR, Lasater TM, Windsor R, Wilkins J, Upegui DI, et al. The accuracy of self-reported smoking status assessed by cotinine test strips. Nicotine Tob Res 2002;4:305-9.

28. Luepker RV, Pechacek TF, Murray DM, Johnson CA, Hund F, et al. Saliva thiocyanate: a chemical indicator of cigarette smoking in adolescents. Am J Public Health 1981;71:1320-4.

29. Post A, Gilljam H, Rosendahl I, Meurling L, Bremberg S, et al. Validity of self reports in a cohort of Swedish adolescent 
smokers and smokeless tobacco (snus) users. Tob Control 2005;14:114-7.

30. Dolcini MM, Adler NE, Lee P, Bauman KE. An assessment of the validity of adolescent self-reported smoking using three biological indicators. Nicotine Tob Res 2003;5: 473-83.

31. Wong SL, Shields M, Leatherdale S, Malaison E, Hammond D. Assessment of validity of self-reported smoking status. Health Rep 2012;23:47-53.

32. Studts JL, Ghate SR, Gill JL, Studts CR, Barnes CN, et al. Validity of self-reported smoking status among participants in a lung cancer screening trial. Cancer Epidemiol Biomarkers Prev 2006;15:1825-8.
33. Bauman KE, Ennett SE. Tobacco use by black and white adolescents: the validity of self-reports. Am J Public Health 1994;84:394-8.

34. Brener ND, Billy JDG, Grady WR. Assessment of factors affecting the validity of self-reported health-risk behavior among adolescents: evidence from the scientific literature. J Adolesc Health 2003;33:436-57.

35. Biglan A, Ary DV. Methodological issues in research on smoking prevention. NIDA Res Monogr 1985;63:170-95.

36. Brittingham A, Tourangeau R, Kay W. Reports of smoking in a national survey: data from screening and detailed interviews, and from self- and interviewer-administered questions. Ann Epidemiol 1998;8:393-401. 